\title{
Chapter 14 \\ Habitat Fragmentation by Railways \\ as a Barrier to Great Migrations \\ of Ungulates in Mongolia
}

\author{
Takehiko Y. Ito, Badamjav Lhagvasuren, Atsushi Tsunekawa \\ and Masato Shinoda
}

\begin{abstract}
Mongolia's Gobi-Steppe Ecosystem is the largest grassland in the world and the habitat of long-distance movement ungulates, such as the Mongolian gazelle (Procapra gutturosa) and the Asiatic wild ass (Equus hemionus). The international railway between Russia and China bisects this habitat, and there has been concern that it may impede the movements of wild ungulates. We tracked ungulate movements on both sides of the Ulaanbaatar-Beijing Railway, and found that most of the tracked animals never crossed the railway. The construction of additional railways to permit mining projects in the area is therefore a further threat to maintaining the great migrations of ungulates across Mongolia.
\end{abstract}

Keywords Asiatic wild ass - Dryland - Grassland - Desert • Long-distance movement - Mongolian gazelle $\cdot$ NDVI - Remote sensing - Satellite tracking • Terrestrial mammal

\section{Introduction}

Mongolia occupies an area of $1,564,100 \mathrm{~km}^{2}$ in central Asia. Mainly due to its low human population density (2.0 ind./ $\mathrm{km}^{2}$ in 2015 for all of Mongolia; National Statistical Office of Mongolia 2016), it harbors the largest grassland in the world. Several species of ungulates inhabit this grassland, including the Mongolian gazelle (Procapra gutturosa), the goitered gazelle (Gazella subgutturosa), and the Asiatic wild ass (Equus hemionus), with some of them, such as the Mongolian gazelle, forming large herds (Fig. 14.1).

T.Y. Ito $(\bowtie) \cdot A$. Tsunekawa

Arid Land Research Center, Tottori University, Tottori, Japan

e-mail: ito@alrc.tottori-u.ac.jp

B. Lhagvasuren

Institute of General and Experimental Biology, Mongolian Academy of Sciences,

Ulaanbaatar, Mongolia

M. Shinoda

Graduate School of Environmental Studies, Nagoya University, Nagoya, Japan

(C) The Author(s) 2017

L. Borda-de-Água et al. (eds.), Railway Ecology,

DOI 10.1007/978-3-319-57496-7_14 


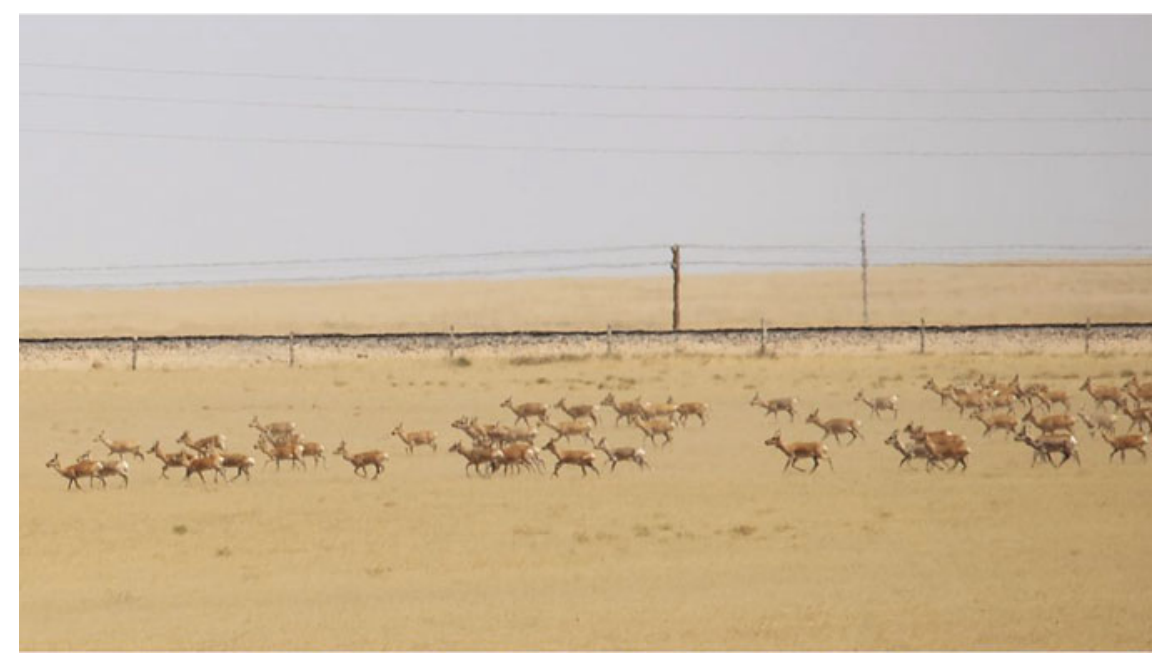

Fig. 14.1 A herd of Mongolian gazelles moving along the Ulaanbaatar-Beijing Railway

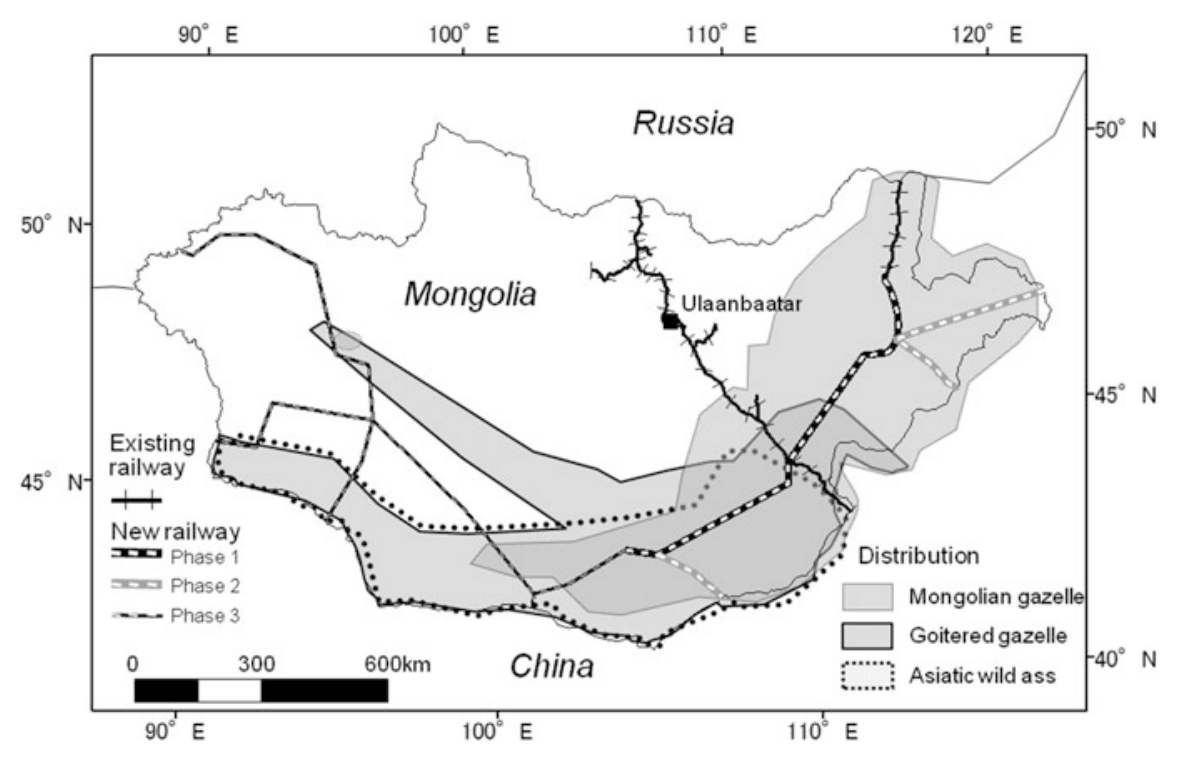

Fig. 14.2 Existing and planned railways in Mongolia and the distributions of the Mongolian gazelle, goitered gazelle, and Asiatic wild ass. Data of the wildlife distribution were downloaded from the IUCN red list website (http://www.iucnredlist.org)

This ecosystem is under threat by human activities, including the presence of the Ulaanbaatar-Beijing Railway and its further development. The name of the railway is deceptive, because it actually connects Russia with China, going through Mongolia's capital, Ulaanbaatar. In doing so, it bisects the country (Fig. 14.2), 
forming a barrier to the movements, including migrations, of several animals, and particularly the Mongolian gazelle. Since 2002, we have been studying the impact of the railway on the Mongolian gazelle by using satellite tracking methods to follow individuals of this species. Our results show that the railway is a barrier to migrations of the gazelle, contributing directly and indirectly to its mortality. Harsh winters in Mongolia force the Mongolian gazelle and other ungulates to perform long-distance movements to find food and the presence of the railway acts a barrier preventing animals from accessing certain food sources.

Here, we report the results of our studies on the impact of the UlaanbaatarBeijing Railway on the movements of the Mongolian gazelle and the spatial distribution of gazelle carcasses that results from the presence of this barrier. Moreover, we assess the impact of further development of the railway network in Mongolia and the need to implement mitigation measures if we want to preserve the great migrations of ungulates across the Mongolian grasslands.

\section{Environments of Mongolia's Gobi-Steppe Ecosystem}

Mongolia's Gobi-Steppe Ecosystem is the world's largest area of intact grassland $\left(827,000 \mathrm{~km}^{2}\right)$, and it is much larger than other globally famous grasslands as wildlife habitat, such as the Greater Yellowstone Ecosystem $\left(108,000 \mathrm{~km}^{2}\right)$ in the western United States and the Serengeti-Mara Ecosystem $\left(25,000 \mathrm{~km}^{2}\right)$ in East Africa (Batsaikhan et al. 2014). The Gobi-Steppe Ecosystem is a wide and intact steppe and semi-desert ecosystem in northern China, Mongolia, and southern Russia where great migrations of wild ungulates still occur. Nomadic pastoralism has been the main lifestyle of the Mongolian people for several thousand years, and the grassland ecosystem has been maintained in relatively good condition compared to that in other regions thanks to low human and livestock densities, low grazing pressure, and movements of people with their livestock between grazing sites to take advantage of better grazing conditions in different seasons and years.

Mongolia has one of the smallest human populations in the world and, although the population is growing, its density in the countryside outside of the capital city was only 1.1 ind. $/ \mathrm{km}^{2}$ in 2015 (National Statistical Office of Mongolia 2016), mainly because half of the country's population is concentrated in the capital city, Ulaanbaatar. The number of livestock, especially goats, has increased since the capitalist system replaced the communist system in 1991, and grassland degradation by overgrazing has been reported in some areas (e.g., Sasaki et al. 2008), although relatively fine and continuous habitats for wildlife remain.

The Gobi-Steppe Ecosystem dominates most of Mongolia, except in mountainous areas and in the northern forests, and is characterized by relatively flat topography. Annual average precipitation in this area is less than about $350 \mathrm{~mm}$, but its interannual variation is large (Vandandorj et al. 2015; Yu et al. 2004), which is typical for drylands. Because precipitation and snowfall increase and temperature decreases from south to north (Morinaga et al. 2003; Nandintsetseg and Shinoda 2011), vegetation correspondingly changes from desert to drylands and forest steppe 
ecosystems. Droughts and severe winters are a cause of high mortality among livestock (Fernandez-Gimenez et al. 2012, 2015; Tachiiri and Shinoda 2012) and wild animals (Kaczensky et al. 2011a).

\section{Railways and Vulnerable Wild Animals in Mongolia}

The Ulaanbaatar-Beijing Railway is an international railway that connects China with Russia thorough Ulaanbaatar (Fig. 14.2). It was built in the 1950s and runs from northwest to southeast; the section that is south of Ulaanbaatar crosses the Gobi-Steppe Ecosystem. Barbed wire fences have been built on both sides of the railway, mainly to prevent accidents with livestock. The influence of the railway on wild animal movements and concomitant population declines has been a cause of concern. Animals can suffer mortality directly when crossing the railway or indirectly because of barrier effects that prevent them from reaching suitable sites for food, water, and reproduction. These concerns led to animal tracking studies (e.g., Ito et al. 2005, 2013a). Mammals inhabiting the grassland ecosystems of Mongolia and showing long-distance movements that are potentially affected by the railway are the Mongolian gazelle, the goitered gazelle, and the Asiatic wild ass (Fig. 14.2; Mallon and Jiang 2009). Current train frequency on the railway is not high (about $1 \mathrm{train} / \mathrm{h}$ in daytime based on our rough observations), and freight trains are more frequent than passenger trains.

Both historically and today, the Mongolian gazelle has had one of the longest migrations among terrestrial animals (Berger 2004; Teitelbaum et al. 2015). Until the 1930s, this species had a distribution that occupied most of the grasslands in northern China, Mongolia, and southern Russia, but since then its distribution has been reduced to the eastern half of Mongolia and to areas close to the border between Mongolia, China, and Russia (Fig. 14.2; Jiang et al. 1998; Lhagvasuren and Milner-Gulland 1997; Mallon 2008b). In the latest IUCN Red List, the Mongolian gazelle is ranked as least concern (LC) due to population estimates over the last 10 years ranging from 400,000 to $2,700,000$ and because its range is expanding toward the northwest (Mallon 2008b).

Mongolia has the largest population of goitered gazelles (40-50\% of the global population; Mallon 2008a). This species has a body size and morphology similar to those of the Mongolian gazelle, but it does not form large herds, and details of its ecology are still unknown. The Asiatic wild ass has lost $70 \%$ of its global range since the 19th century, and at present, more than $75 \%$ of the population (about 55,000 animals) lives in Mongolia (Kaczensky et al. 2011a, 2015; Reading et al. 2001).

\section{Movement Ecology of Mongolian Gazelles}

Among ungulates, the Mongolian gazelle is the most well studied species in terms of the impact of the Ulaanbaatar-Beijing Railway on its movements. Although the species' behavioral ecology has not been fully elucidated, Mongolian gazelles 
inhabit grassland and semi-desert areas and sometimes form large herds of several thousand animals. Under severe climate conditions, the estimated lifespan in the wild is 7-8 years (Batsaikhan et al. 2010). The rutting period is in winter, and females over 2 years old usually give birth to one calf in late June or early July (Lhagvasuren and Milner-Gulland 1997). The long-distance movements of this species for migration or nomadism were already understood before scientific tracking started (Jiang et al. 1998; Lhagvasuren and Milner-Gulland 1997). Since then, analyses of gazelle movements in relation to habitat selection and environmental factors, including the presence of a railway, have brought many new findings on the ecology of this species and related conservation issues.

Using modern technology, we have been able to prove the capability of the Mongolian gazelle to travel long distances. For instance, Argos systems and GPS with satellite communication systems have been used to track wild ungulates in Mongolia (Kaczensky et al. 2010). We showed that Mongolian gazelles moved distances greater than $300 \mathrm{~km}$ (the maximum linear distance between two locations traveled by one individual gazelle in a year) and changed their range seasonally (Ito et al. 2006, 2013b). The gazelles moved more than $100 \mathrm{~km}$ per week during some periods of the year, whereas the distances moved were short in other periods. Interannual differences in the seasonal range locations among the same individuals were also observed, which in some cases were larger than $300 \mathrm{~km}$ in winter, suggesting nomadic movements rather than typical seasonal migrations between specific locations (Ito et al. 2013b; Olson et al. 2010).

Understanding why and how animals move long distances is important both for purely scientific purposes and for conservation. Studies on this topic have shown that environmental factors play a pivotal role, and the normalized-difference vegetation index (NDVI) has mainly been used as an index of the amount of live plants in studies of the Mongolian gazelle. For instance, Leimgruber et al. (2001) showed that the winter and the calving grounds in the eastern steppes of Mongolia (identified based on expert knowledge of scientists and pastoralists, but not tracking data), had the highest NDVI scores during periods when gazelles used these areas. In a study comparing gazelle distribution and NDVI values in different seasons in the eastern steppes, Mueller et al. (2008) showed that gazelles preferred areas with intermediate NDVI values in the spring and autumn. Similarly, during a drought period in September 2005, Olson et al. (2009a) reported a mega-herd of more than 200,000 gazelles in areas with a high probability of gazelle occurrence predicted by a NDVI-based model. In the southeastern Gobi, the shifts in NDVI values between the summer and winter ranges explained the gazelles' seasonal movements (Ito et al. 2006), and interannual differences in the spatial distribution of NDVI explained the interannual differences in the seasonal range of the tracked gazelles (Ito et al. 2013b). The interannual differences in locations were much larger in winter than in summer, likely because of the large differences in the spatial distribution of snow cover. Avoidance of areas with deep snow cover by Mongolian gazelles was also reported in Inner Mongolia, China (Luo et al. 2014). In addition, regional differences in the amount of vegetation across the species' spatial distribution also led to intraspecific variations of their movement patterns (Imai et al. 2017). 
The spatial distribution and seasonal change of food plants are considered to be important factors determining the movement patterns of ungulates (Mueller and Fagan 2008). Therefore, environmental unpredictability at the landscape level affects movement patterns of animals through seasonal and interannual changes in food availability. Mongolian gazelles in the eastern steppe of Mongolia have nomadic movements that are more irregular than those of other ungulate species, such as caribou (Rangifer tarandus granti) in Alaska, which exhibit regular seasonal migration, or the guanaco (Lama guanicoe) in Argentina and moose (Alces alces) in the northeastern United States, both of which move shorter distances with more predictable movements (Mueller et al. 2011). Therefore, in order to conserve nomadic animals, like Mongolian gazelles, that live in unpredictable environments, the maintenance of good environmental conditions and access to vast areas are essential, especially during those periods when conditions become unsuitable in much of their ranges.

\section{Effects of the Ulaanbaatar-Beijing Railway on Wild Ungulates}

\section{Barrier Effect of the Existing Railway}

The barrier effect of the Ulaanbaatar-Beijing Railway on the movements of wild ungulates in Mongolia has been apparent since the beginning of satellite tracking of these animals. We first conducted satellite tracking of Mongolian gazelles in 2002 (Ito et al. 2005, 2006). In October 2002, two female gazelles were captured on the southwestern side of the railway and collared with a satellite transmitter. The distance between the site of capture and the railway was about $7 \mathrm{~km}$. Although both gazelles were captured at exactly the same place, their movements after release were different (Fig. 14.3). This is a small sample size, but it is representative of the movements of more individuals because at the time when the animals were captured, the gazelles were part of a herd with several hundred animals. The different movements of the two gazelles also indicate loose relations among gazelle individuals. Sometimes Mongolian gazelles form large herds, whereas other times they separate into relatively small groups. Such uncoordinated movement patterns were also reported in a comparative study of the Mongolian gazelle, caribou, guanaco, and moose (Mueller et al. 2011).

The two gazelles captured near the railway moved along it for a year, but never crossed it (Ito et al. 2005). They moved closer to the railway during winter (October-March) than during summer (April-September), and the nearest distances of the two gazelles to the railway were 0.3 and $1.8 \mathrm{~km}$, respectively (Fig. 14.3). These results suggest that the railway is a barrier for gazelle movements mainly because of the fences along the rails. Some wildlife crossing locations exist along the railway (Fig. 14.4), but our data suggest that these crossings are ineffective, probably due to their limited number and their lack of suitable natural features that could reduce the natural wariness of the gazelles. 


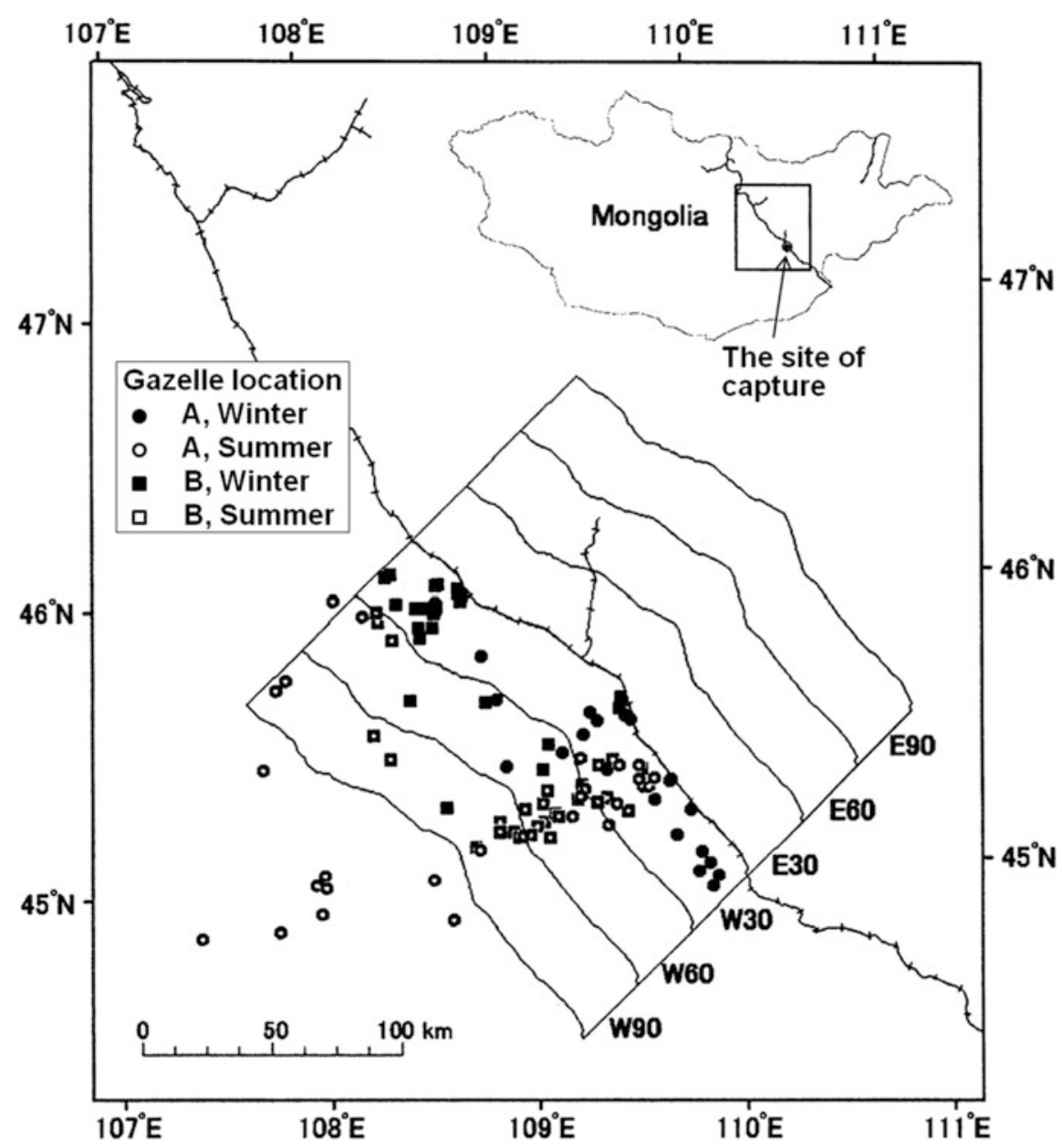

Fig. 14.3 Locations of two tracked Mongolian gazelles from 2002 to 2003 in Mongolia, and the zones in which the normalized-difference vegetation index (NDVI) was analyzed. Zones W30, W60, and W90 are 0-30, 30-60, and 60-90 km northwest of the railway, respectively, and zones E30, E60, and E90 are 0-30, 30-60, and 60-90 km southeast of the railway, respectively. The hatched line represents the railway (from Ito et al. 2005)

To understand why the gazelles used areas near the railway during the winter and whether there were any disadvantages for gazelles caused by being restricted to only one side of the railway, we compared NDVI values on both sides of the railway. We established three $30-\mathrm{km}$ zones on each side of the railway, parallel to the rails (Fig. 14.3). These zones spanned most northern and southern gazelle locations observed during the winter. We detected a significant gradient of NDVI values from 17 November to 2 December 2002, the period when the gazelles moved the greatest distance, from southwest to northeast (Ito et al. 2005). The highest average NDVI value was in the 30 - to $60-\mathrm{km}$ northeastern zone (Fig. 14.5), suggesting that the 

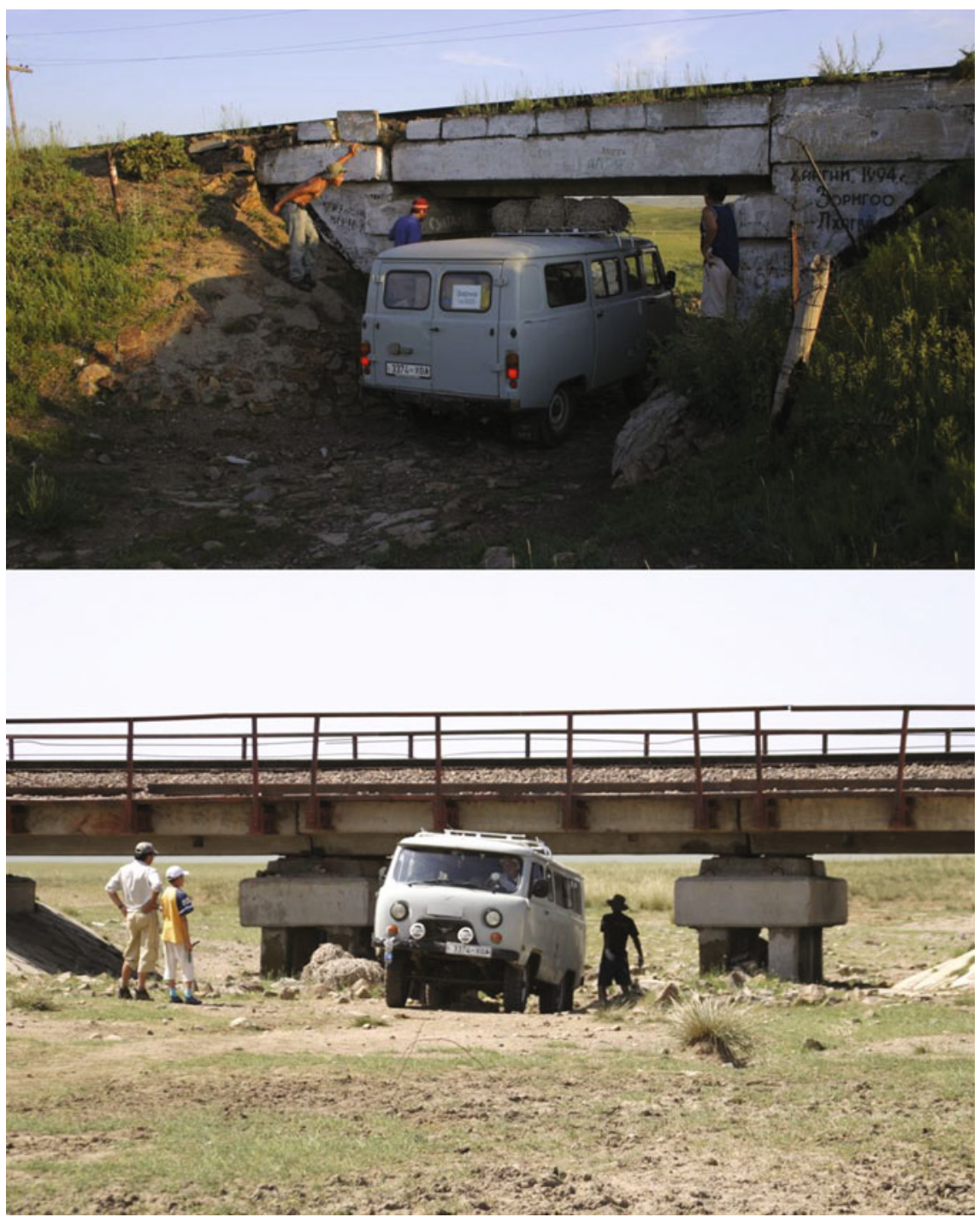

Fig. 14.4 Underpasses on the Ulaanbaatar-Beijing Railway

tracked gazelles, (and thus, many gazelles living on the southwestern side of the railway) could not use better sites existing on the opposite side due to the barrier caused by the railway.

The barrier effect of the railway became more evident as more animal tracking data were gathered. An Asiatic wild ass tracked from July 2005 to February 2006 also moved along the southwestern side of the railway but did not cross it (Kaczensky et al. 2006, 2011b). The railway now likely forms the eastern edge of 
Fig. 14.5 Average normalized-difference vegetation index (NDVI) in each zone adjacent to the railway from 17 November to 2 December 2002. Error bars represent $95 \%$ confidence intervals. See Fig. 14.3 for explanation of zone names (from Ito et al. 2005)

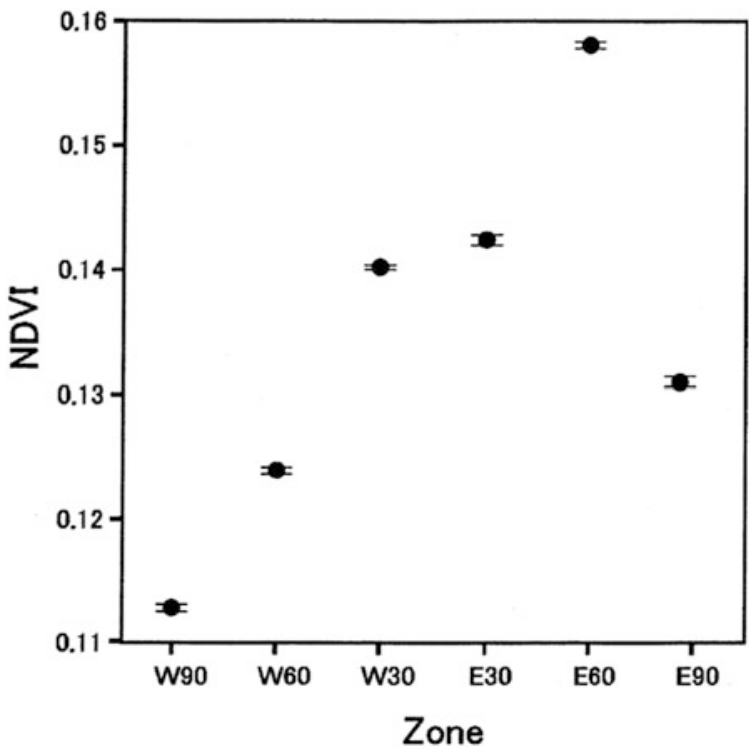

the current Asiatic wild ass distribution because no wild ass has been observed on the eastern side for many years, despite the existence of suitable habitat on the northeastern side of the railway (Kaczensky et al. 2011b, 2015). Further data on tracked Mongolian gazelles have confirmed that the railway impeded 24 gazelles tracked between 2002 and 2012 from crossing to both sides (Fig. 14.6; Ito et al. 2013a), except for one individual (Olson 2012).

International border fences further exacerbate the fragmentation of the landscape and have a similar barrier effect on wild ungulates. Almost none of the tracked ungulates in Mongolia crossed the borders (Fig. 14.6; Ito et al. 2013a; Kaczensky et al. 2006, 2008, 2011a; Olson 2012; Olson et al. 2009b), except for one reported case of an Asiatic wild ass in western Mongolia (Kaczensky et al. 2011a). These results indicate that the railway and the border fences are likely causes of habitat fragmentation and impediments to long-distance movements of ungulates.

\section{Influences of the Barrier Effect on Wild Ungulates}

What are the problems caused by railway barrier effects on wild ungulates? Although the railway bisects Mongolia's Gobi-Steppe Ecosystem, each part of the ecosystem is still vast. The seasonality of the ungulates' location is a key to evaluate how the railway influences the animals restricted to one side of this barrier. Tracked Mongolian gazelles and Asiatic wild asses used areas far from the barriers during summer but used areas close to the railway and the borders during winter (Fig. 14.7; Ito et al. 2005, 2013a). The only case of a tracked wild ass crossing the border to China and returning to Mongolia was observed during the harsh winter 

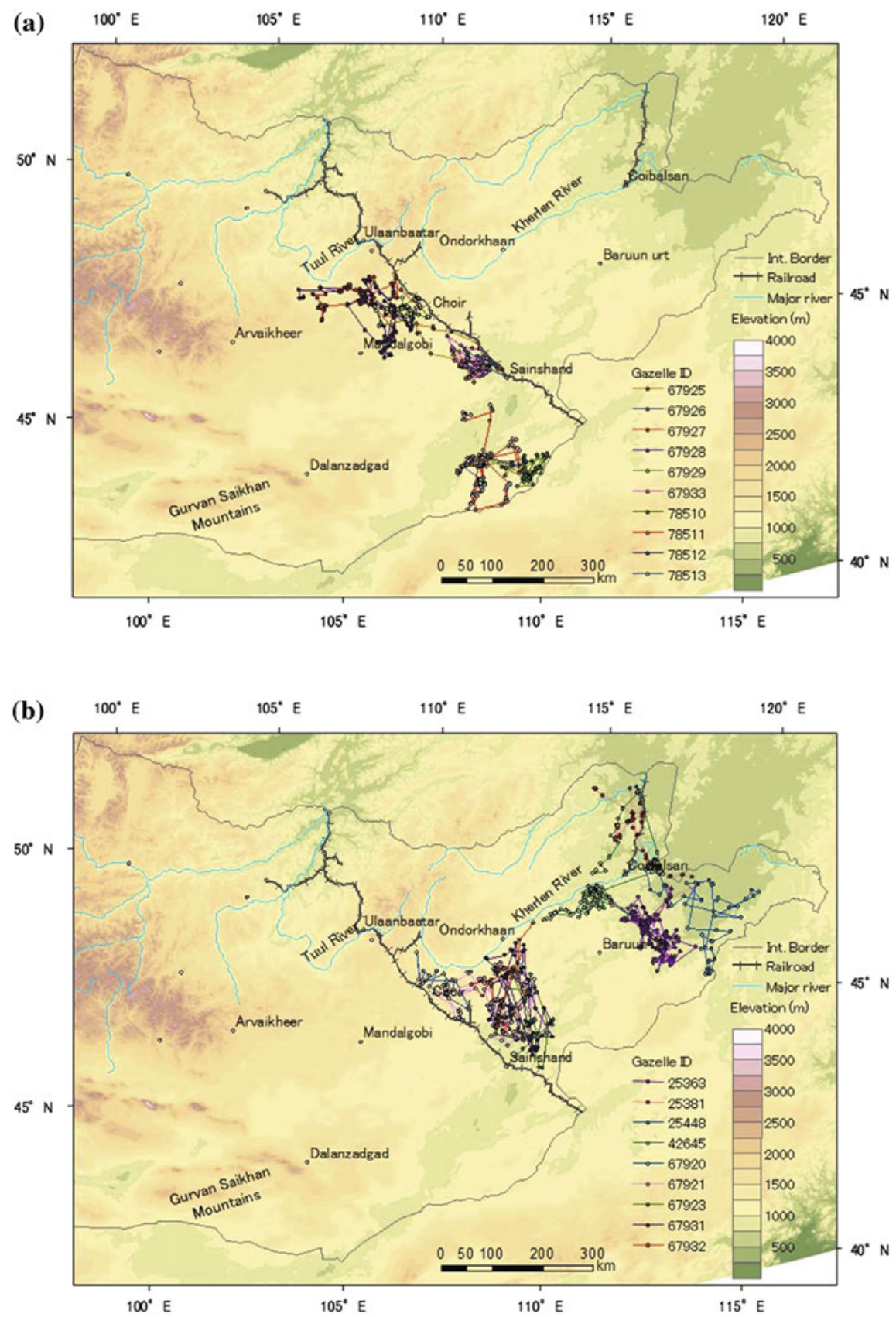

Fig. 14.6 Movements of the tracked Mongolian gazelles: a gazelles captured on the southwestern side of the Ulaanbaatar-Beijing Railway in 2007, and b gazelles captured on the northeastern side from 2003. The tracking continued until 2012 (from Ito et al. 2013a) 
(dzud) of 2009/2010 in western Mongolia (Kaczensky et al. 2011a), but no other tracked animals ever crossed it. The reason why animals tend to be closer to the railway in the winter is likely to be related to food availability. During the plant growing period (summer in Mongolia), suitable areas for herbivores are widespread. In contrast, the period from winter to early spring is the severest period for wild and livestock animals in Mongolia because of low temperatures and poor food availability caused by plant withering, plant consumption by continuous grazing, and snow cover on the vegetation. Herbivorous animals, therefore, have to move in order to find suitable sites with enough vegetation to survive during this harsh time, and many animals consequently reach areas close to the railway and international borders, which often have fences.

The limitation of movements and habitat use by ungulates may lead to higher mortality. If suitable sites for ungulates are mainly located on the opposite side of the barriers during winter, the animals may not get enough food to survive. Therefore we predicted a higher density of carcasses of Mongolian gazelles along the Ulaanbaatar-Beijing Railway than in remote areas away from the railway. Indeed, many carcasses were actually found near the railway, although we have not compared this with the carcass density in remote areas. We conducted a carcass survey along a 630-km section of the railway in June 2005 and found a total of 241 Mongolian gazelle carcasses. Carcass densities differed not only between regions but also between the southwestern and northeastern sides of the railway (Fig. 14.8; Ito et al. 2008). A similar carcass survey was conducted in summer 2011, and 393

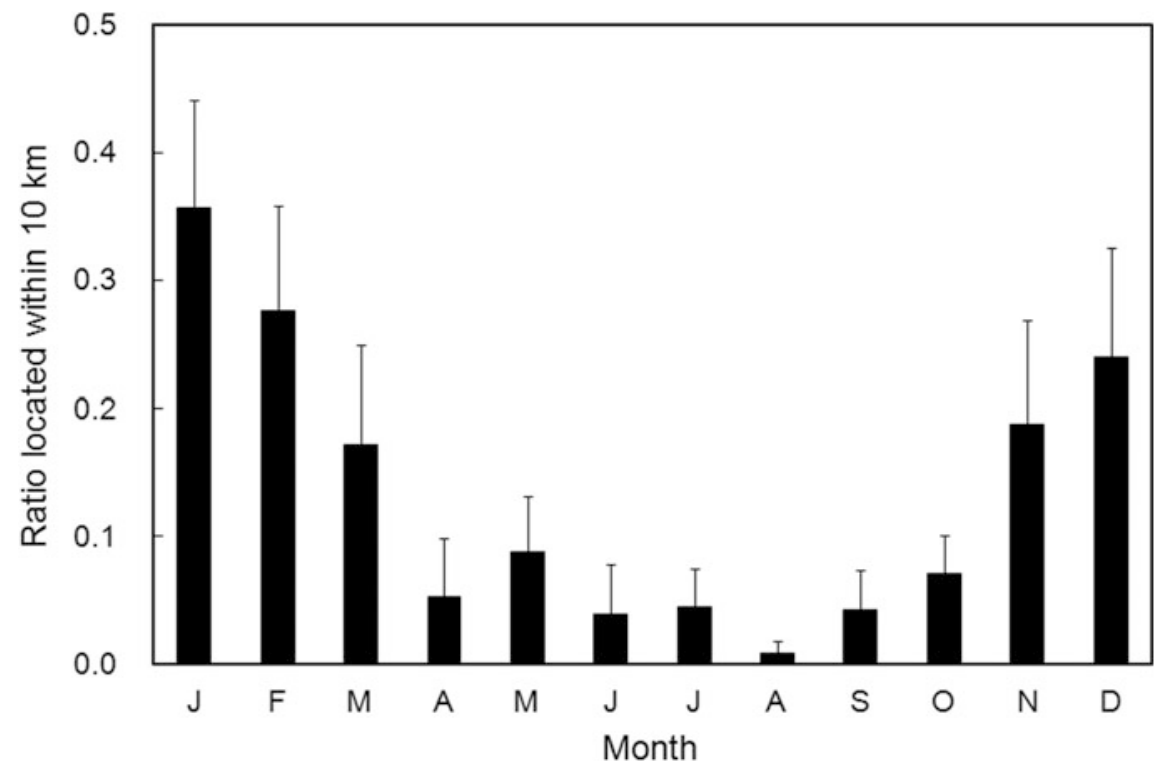

Fig. 14.7 Monthly ratio (mean + SE) of location data within $10 \mathrm{~km}$ of the anthropogenic barriers (the railway and the international border fence) to all monthly location data for tracked Mongolian gazelles that used areas within $10 \mathrm{~km}$ of the barriers at least once during the tracking periods $(n=16$; from Ito et al. 2013a) 


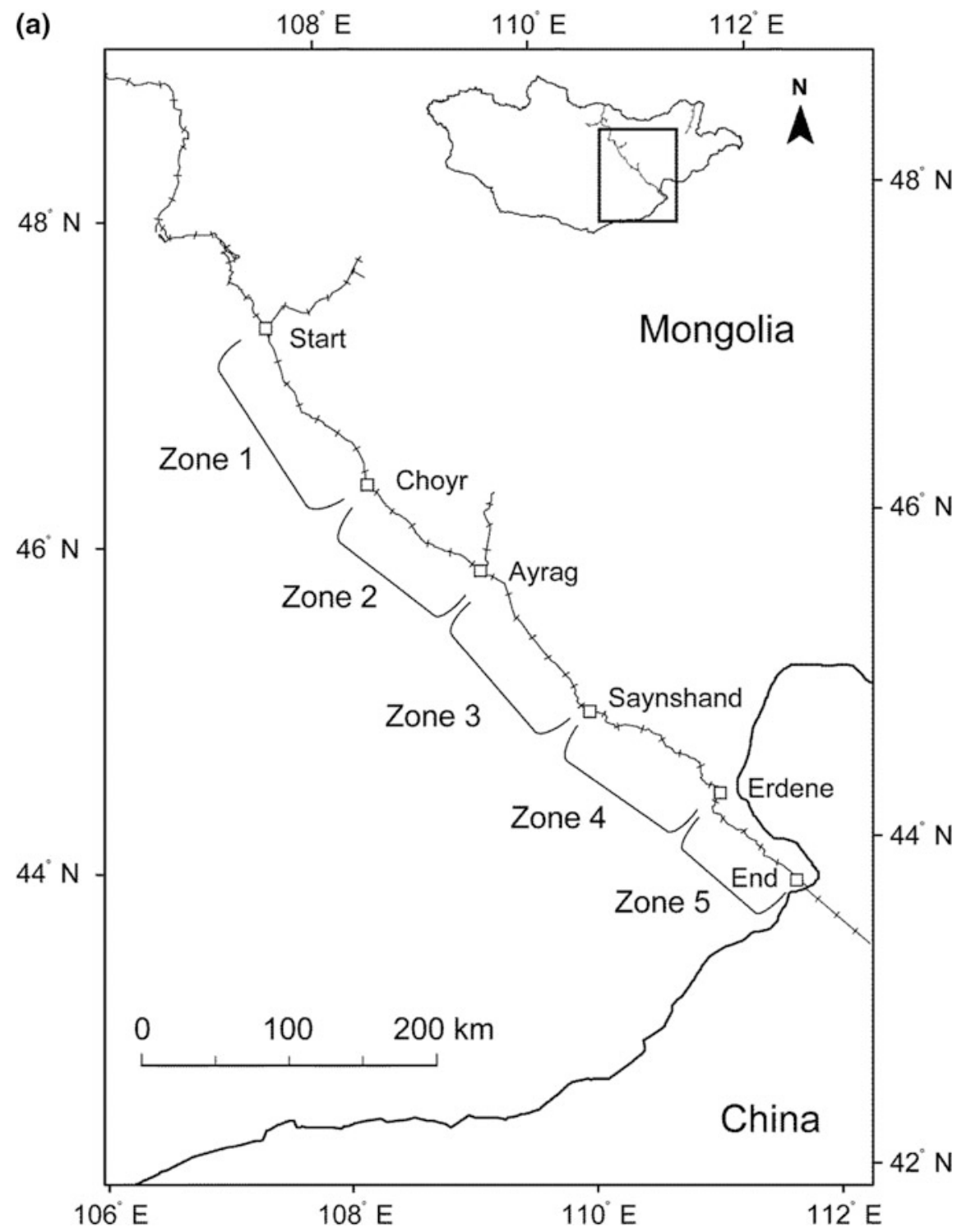

Fig. 14.8 a Study area of a Mongolian gazelle carcass census conducted along the UlaanbaatarBeijing Railway in June 2005 and ranges of each zone. Open squares are locations of major towns and the start- and end-points of the carcass census. The hatched line represents the railway. b Carcass numbers of Mongolian gazelles on the southwestern and northeastern sides of the Ulaanbaatar-Beijing Railway in each zone. We categorized carcasses according to whether we found them outside or inside railway fences (from Ito et al. 2008) 


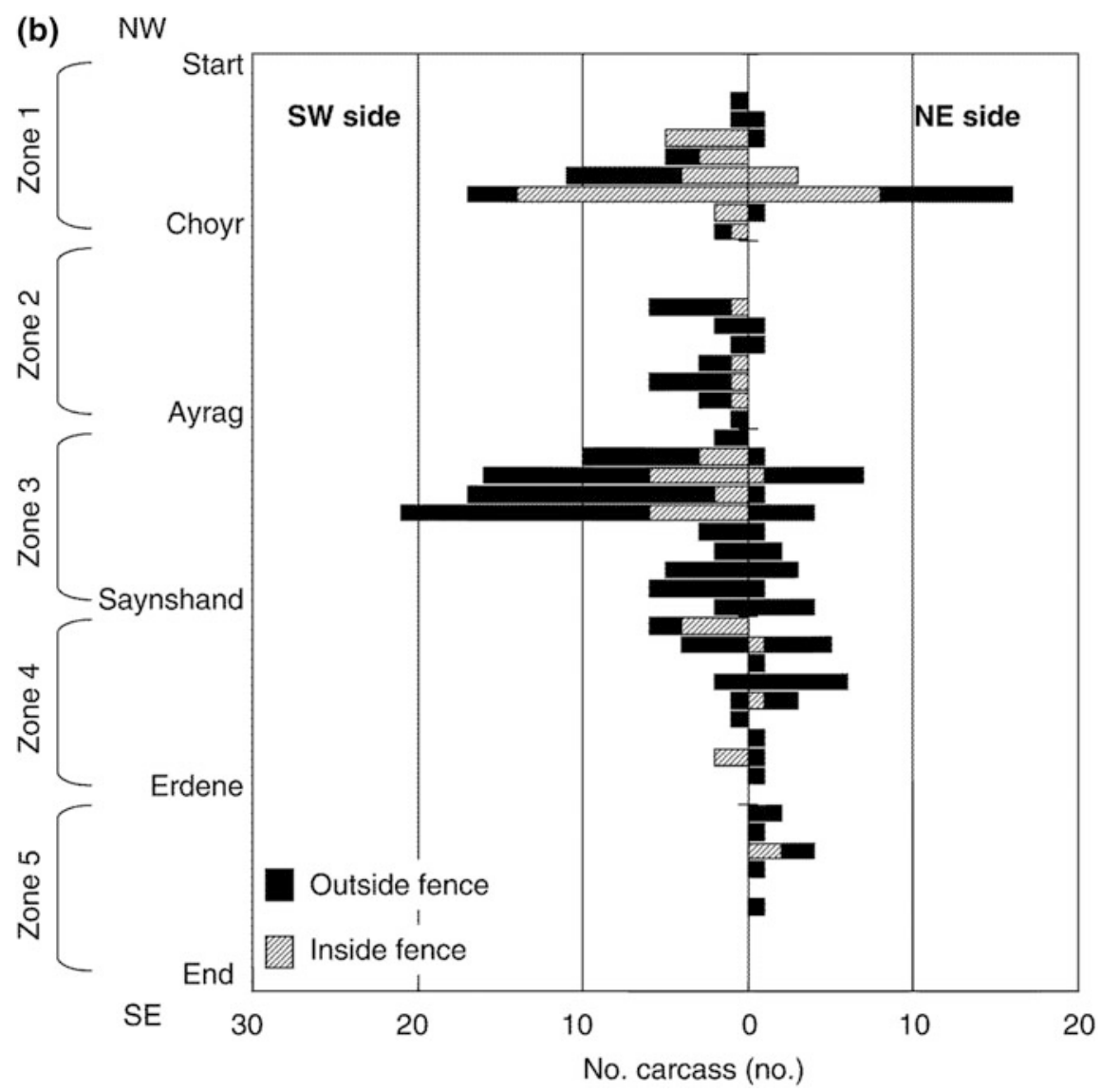

Fig. 14.8 (continued)

carcasses were recorded (Olson 2012). Although the carcass distribution patterns in different years were similar, there were also some differences. An area of high carcass density existed to the southeast of Ayrag Town in the 2005 survey (Fig. 14.8), but a high density was found to the northwest of the town in the 2011 survey. We attribute this interannual difference among areas of high carcass density to the high environmental unpredictability, which leads to changes in the locations of suitable sites for wild ungulates. Thus, the areas with high carcass density in one year do not necessarily indicate that these are the best sites to implement wildlife crossings. However, because Mongolian gazelles likely have a learning capacity, the sites are still good candidates given that gazelles had previously used these areas. For example, some tracked gazelles came back from several hundred kilometers to the same location in the following summer (Ito et al. 2013b).

Carcasses were also found inside the fenced area (Fig. 14.8), suggesting that the fences did not form a total barrier to wild ungulates. The existence of carcasses inside the fences might be explained by the fact that plant biomass is more abundant 


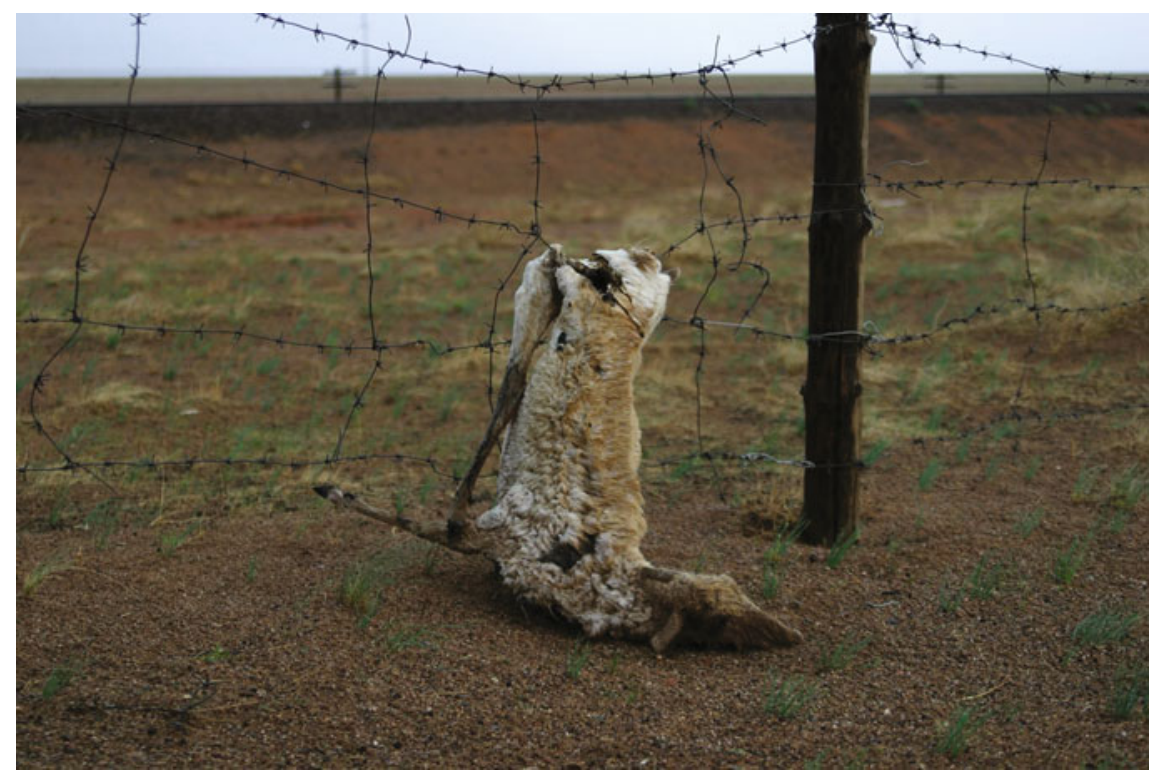

Fig. 14.9 Carcass of a Mongolian gazelle entangled in a railway fence of the Ulaanbaatar-Beijing Railway

inside the fence at the beginning of winter, because these areas are not usually grazed by livestock or wild ungulates during summer. Therefore, the area inside the fences may be attractive for herbivores in winter, leading to some ungulates trying to enter it. Once inside the fenced area, the animal may not be able to find suitable locations to jump or crawl out of the fence again or may become too weak to do so. Note, however, that we found some carcasses entangled in the fence's barbed wires (Fig. 14.9), suggesting that the fence itself is a cause of mortality.

Several questions remain concerning the interpretation of areas of high carcass density. For example, was animal density simply higher in these areas? Did a large number of animals try to cross there because the area looked easy to pass? Did the area have any intrinsic factors that cause higher mortality? For example, do the fence structures easily entangle animals, making it difficult to escape once inside?

Finally, the genetic structure of the gazelle populations sampled in the 2005 survey was not different between the two sides of the railway (Okada et al. 2012, 2015). This can be explained by animals occasionally crossing the railway via underpasses and areas with broken fences, and other permeable areas. In addition, the survey was conducted just about 50 years after the railway's construction, which is not enough time for genetic differentiation given the relatively long lifespan of the species. Therefore, the genetic structure of wild ungulate populations may differentiate in the future if the railway barrier effects persist. 


\section{Railway Development as a Threat to Wildlife}

Mongolia's Gobi-Steppe Ecosystem is facing the threats of new railway development (Batsaikhan et al. 2014). Large mining projects are being developed in southern Mongolia, and there are plans to develop a railway network to transport mining products and connect cities. In fact, construction has already started in some regions. The new railways run through the central distribution ranges of the Mongolian gazelle, the goitered gazelle, and the Asiatic wild ass (Fig. 14.2). If the new railways have barrier effects similar to those of the existing railway, then the ungulates' habitat will be further fragmented into smaller areas. The railways also cross the distribution ranges of the critically endangered wild Bactrian camel (Camelus ferus), the reintroduced Przewalski's horse (Equus ferus przewalskii), and the saiga antelope (Saiga tatarica). Przewalski's horse was once extinct in the wild, but it is currently only ranked as an endangered species by the IUCN Red List because its populations have successfully increased after its reintroduction (King et al. 2016). However, future recovery of the distributions and population numbers of these endangered ungulates may be threatened by the new railways.

Railways also attract human activities to their vicinities that have potential negative impacts on wildlife. Olson et al. (2011) reported that in eastern Mongolia, the Mongolian gazelle density was lower in areas with households than in areas with no households. One detrimental impact of an increased human population is the increase in livestock. Mongolian gazelles have food habits similar to those of domestic sheep and goats (Campos-Arceiz et al. 2004; Yoshihara et al. 2008), and the food habits of the Asiatic wild ass are similar to those of the domestic horse (Taro Sugimoto, personal communication). Thus, food competition between wild ungulates and livestock would likely become more severe if the livestock density increases. Hunting and poaching by humans may also decrease populations of wild ungulates.

Habitat fragmentation has caused regional extinctions of many animal species in various regions of the world (see Chap. 4). Even if the ungulate populations in Mongolia's Gobi-Steppe Ecosystem persist in the smaller habitat fragments produced by railways, their great migrations might disappear in the future. These spectacular migrations need both continuous vast areas and large animal populations. To maintain large wild ungulate populations in Mongolia, it is essential that the accessibility to wide ranges is maintained, due to the high environmental unpredictability in this region.

To maintain accessibility after the construction of new railways, it will be necessary to construct suitable wildlife crossings at regular intervals. Sections without fences in areas with low livestock densities will be also effective. In addition, maintaining the ecosystem in good condition is also necessary, for example, by avoiding land-use changes to farmland, human residential areas, or road networks and by avoiding land degradation due to overgrazing by livestock. Maintaining good conditions of the ecosystem across wide ranges will be effective for the conservation of both wild ungulates and biodiversity in the ecosystem. 
Acknowledgements This study was funded by the Japan Ministry of Education, Culture, Sports, Science, and Technology's Grants-in-Aid for Scientific Research 14405039, 18255002, 20255001, 24510326, 25220201, 15K06931.

\section{References}

Batsaikhan, N., Buuveibaatar, B., Chimed, B., Enkhtuya, O., Galbrakh, D., Ganbaatar, O., et al. (2014). Conserving the world's finest grassland amidst ambitious national development. Conservation Biology, 28, 1736-1739.

Batsaikhan, N., Samiya, R., Shar, S., \& King, S. R. B. (2010). A field guide to the mammals of Mongolia. London: Zoological Society of London.

Berger, J. (2004). The last mile: How to sustain long-distance migration in mammals. Conservation Biology, 18, 320-331.

Campos-Arceiz, A., Takatsuki, S., \& Lhagvasuren, B. (2004). Food overlap between Mongolian gazelles and livestock in Omnogobi, southern Mongolia. Ecological Research, 19, 455-460.

Fernandez-Gimenez, M. E., Batkhishig, B., \& Batbuyan, B. (2012). Cross-boundary and cross-level dynamics increase vulnerability to severe winter disasters $(d z u d)$ in Mongolia. Global Environmental Change-Human and Policy Dimensions, 22, 836-851.

Fernandez-Gimenez, M. E., Batkhishig, B., Batbuyan, B., \& Ulambayar, T. (2015). Lessons from the $d z u d$ : Community-based rangeland management increases the adaptive capacity of Mongolian herders to winter disasters. World Development, 68, 48-65.

Imai, S., Ito, T. Y., Kinugasa, T., Shinoda, M., Tsunekawa, A., \& Lhagvasuren, B. (2017). Effects of spatiotemporal heterogeneity of forage availability on annual range size of Mongolian gazelles. Journal of Zoology, 301, 133-140.

Ito, T. Y., Miura, N., Lhagvasuren, B., Enkhbileg, D., Takatsuki, S., Tsunekawa, A., et al. (2005). Preliminary evidence of a barrier effect of a railroad on the migration of Mongolian gazelles. Conservation Biology, 19, 945-948.

Ito, T. Y., Miura, N., Lhagvasuren, B., Enkhbileg, D., Takatsuki, S., Tsunekawa, A., et al. (2006). Satellite tracking of Mongolian gazelles (Procapra gutturosa) and habitat shifts in their seasonal ranges. Journal of Zoology, 269, 291-298.

Ito, T. Y., Okada, A., Buuveibaatar, B., Lhagvasuren, B., Takatsuki, S., \& Tsunekawa, A. (2008). One-sided barrier impact of an international railroad on Mongolian gazelles. Journal of Wildlife Management, 72, 940-943.

Ito, T. Y., Lhagvasuren, B., Tsunekawa, A., Shinoda, M., Takatsuki, S., Buuveibaatar, B., et al. (2013a). Fragmentation of the habitat of wild ungulates by anthropogenic barriers in Mongolia. PLOS ONE, 8, e56995.

Ito, T. Y., Tsuge, M., Lhagvasuren, B., Buuveibaatar, B., Chimeddorj, B., Takatsuki, S., et al. (2013b). Effects of interannual variations in environmental conditions on seasonal range selection by Mongolian gazelles. Journal of Arid Environments, 91, 61-68.

Jiang, Z., Takatsuki, S., Gao, Z., \& Jin, K. (1998). The present status, ecology and conservation of the Mongolian gazelle, Procapra gutturosa: A review. Mammal Study, 23, 63-78.

Kaczensky, P., Sheehy, D. P., Johnson, D. E., Walzer, C., Lhkagvasuren, D., \& Sheehy, C. M. (2006). Room to roam? The threat to khulan (wild ass) from human intrusion. Washington, D. C.: World Bank.

Kaczensky, P., Ganbaatar, O., von Wehrden, H., \& Walzer, C. (2008). Resource selection by sympatric wild equids in the Mongolian Gobi. Journal of Applied Ecology, 45, 1762-1769.

Kaczensky, P., Ito, T. Y., \& Walzer, C. (2010). Satellite telemetry of large mammals in Mongolia: What expectations should we have for collar function? Wildlife Biology in Practice, 6, 108-126. 
Kaczensky, P., Ganbataar, O., Altansukh, N., Enkhsaikhan, N., Stauffer, C., \& Walzer, C. (2011a). The danger of having all your eggs in one basket: Winter crash of the re-introduced Przewalski's horses in the Mongolian Gobi. PLoS ONE, 6, e28057.

Kaczensky, P., Kuehn, R., Lhagvasuren, B., Pietsch, S., Yang, W. K., \& Walzer, C. (2011b). Connectivity of the Asiatic wild ass population in the Mongolian Gobi. Biological Conservation, 144, 920-929.

Kaczensky, P., Lkhagvasuren, B., Pereladova, O., Hemami, M., \& Bouskila, A. (2015). Equus hemionus. The IUCN Red List of Threatened Species 2015, e.T7951A45171204. doi:10.2305/ IUCN.UK.2015-4.RLTS.T7951A45171204.en

King, S. R. B., Boyd, L., Zimmerman, W., \& Kendall, B. E. (2016). Equus ferus. The IUCN Red List of Threatened Species 2016, e.T41763A97204950.

Leimgruber, P., McShea, W. J., Brookes, C. J., Bolor-Erdene, L., Wemmer, C., \& Larson, C. (2001). Spatial patterns in relative primary productivity and gazelle migration in the eastern steppes of Mongolia. Biological Conservation, 102, 205-212.

Lhagvasuren, B., \& Milner-Gulland, E. J. (1997). The status and management of the Mongolian gazelle Procapra gutturosa population. Oryx, 31, 127-134.

Luo, Z., Liu, B., Liu, S., Jiang, Z., \& Halbrook, R. S. (2014). Influences of human and livestock density on winter habitat selection of Mongolian gazelle (Procapra gutturosa). Zoological Science, 31, 20-30.

Mallon, D. P. (2008a). Gazelle subgutturosa. The IUCN Red List of Threatened Species 2008, e. T8976A12945246. doi:10.2305/IUCN.UK.2008.RLTS.T8976A12945246.en/

Mallon, D. P. (2008b). Procapra gutturosa. The IUCN Red List of Threatened Species 2008, e. T18232A7858611. doi:10.2305/IUCN.UK.2008.RLTS.T18232A7858611.en

Mallon, D. P., \& Jiang, Z. (2009). Grazers on the plains: Challenges and prospects for large herbivores in central Asia. Journal of Applied Ecology, 46, 516-519.

Morinaga, Y., Tian, S. F., \& Shinoda, M. (2003). Winter snow anomaly and atmospheric circulation in Mongolia. International Journal of Climatology, 23, 1627-1636.

Mueller, T., \& Fagan, W. F. (2008). Search and navigation in dynamic environments: From individual behaviors to population distributions. Oikos, 117, 654-664.

Mueller, T., Olson, K. A., Dressler, G., Leimgruber, P., Fuller, T. K., Nicolson, C., et al. (2011). How landscape dynamics link individual- to population-level movement patterns: A multispecies comparison of ungulate relocation data. Global Ecology and Biogeography, 20, 683-694.

Mueller, T., Olson, K. A., Fuller, T. K., Schaller, G. B., Murray, M. G., \& Leimgruber, P. (2008). In search of forage: Predicting dynamic habitats of Mongolian gazelles using satellite-based estimates of vegetation productivity. Journal of Applied Ecology, 45, 649-658.

Nandintsetseg, B., \& Shinoda, M. (2011). Seasonal change of soil moisture in Mongolia: Its climatology and modelling. International Journal of Climatology, 31, 1143-1152.

National Statistical Office of Mongolia. (2016). Mongolian statistical information service. http:// www.1212.mn/en/contents/stats/contents_stat_fld_tree_html.jsp

Okada, A., Ito, T. Y., Buuveibaatar, B., Lhagvasuren, B., \& Tsunekawa, A. (2012). Genetic structure of Mongolian gazelle (Procapra gutturosa): the effect of railroad and demographic change. Mongolian Journal of Biological Sciences, 10, 59-66.

Okada, A., Ito, T. Y., Buuveibaatar, B., Lhagvasuren, B., \& Tsunekawa, A. (2015). Genetic structure in Mongolian gazelles based on mitochondrial and microsatellite markers. Mammalian Biology, 80, 303-311.

Olson, K. (2012). Wildlife crossing options along existing and planned Mongolian railway corridors. Washington D.C.: World Bank.

Olson, K. A., Fuller, T. K., Mueller, T., Murray, M. G., Nicolson, C., Odonkhuu, D., et al. (2010). Annual movements of Mongolian gazelles: Nomads in the eastern steppe. Journal of Arid Environments, 74, 1435-1442.

Olson, K. A., Mueller, T., Kerby, J. T., Bolortsetseg, S., Leimgruber, P., Nicolson, C. R., et al. (2011). Death by a thousand huts? Effects of household presence on density and distribution of Mongolian gazelles. Conservation Letters, 4, 304-312. 
Olson, K. A., Mueller, T., Bolortsetseg, S., Leimgruber, P., Fagan, W. F., \& Fuller, T. K. (2009a). A mega-herd of more than 200,000 Mongolian gazelles Procapra gutturosa: a consequence of habitat quality. Oryx, 43, 149.

Olson, K. A., Mueller, T., Leimgruber, P., Nicolson, C., Fuller, T. K., Bolortsetseg, S., et al. (2009b). Fences impede long-distance Mongolian gazelle (Procapra gutturosa) movements in drought-stricken landscapes. Mongolian Journal of Biological Sciences, 7, 45-50.

Reading, R. P., Mix, H. M., Lhagvasuren, B., Feh, C., Kane, D. P., Dulamtseren, S., et al. (2001). Status and distribution of khulan (Equus hemionus) in Mongolia. Journal of Zoology, 254, 381-389.

Sasaki, T., Okayasu, T., Jamsran, U., \& Takeuchi, K. (2008). Threshold changes in vegetation along a grazing gradient in Mongolian rangelands. Journal of Ecology, 96, 145-154.

Tachiiri, K., \& Shinoda, M. (2012). Quantitative risk assessment for future meteorological disasters: Reduced livestock mortality in Mongolia. Climatic Change, 113, 867-882.

Teitelbaum, C. S., Fagan, W. F., Fleming, C. H., Dressler, G., Calabrese, J. M., Leimgruber, P., et al. (2015). How far to go? Determinants of migration distance in land mammals. Ecology Letters, 18, 545-552.

Vandandorj, S., Gantsetseg, B., \& Boldgiv, B. (2015). Spatial and temporal variability in vegetation cover of Mongolia and its implications. Journal of Arid Land, 7, 450-461.

Yoshihara, Y., Ito, T. Y., Lhagvasuren, B., \& Takatsuki, S. (2008). A comparison of food resources used by Mongolian gazelles and sympatric livestock in three areas in Mongolia. Journal of Arid Environments, 72, 48-55.

Yu, F., Price, K. P., Ellis, J., Feddema, J. J., \& Shi, P. (2004). Interannual variations of the grassland boundaries bordering the eastern edges of the Gobi Desert in central Asia. International Journal of Remote Sensing, 25, 327-346.

Open Access This chapter is licensed under the terms of the Creative Commons Attribution 4.0 International License (http://creativecommons.org/licenses/by/4.0/), which permits use, sharing, adaptation, distribution and reproduction in any medium or format, as long as you give appropriate credit to the original author(s) and the source, provide a link to the Creative Commons license and indicate if changes were made.

The images or other third party material in this chapter are included in the chapter's Creative Commons license, unless indicated otherwise in a credit line to the material. If material is not included in the chapter's Creative Commons license and your intended use is not permitted by statutory regulation or exceeds the permitted use, you will need to obtain permission directly from the copyright holder.

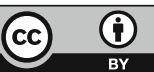

